\title{
Marianne A. Larsen \\ The Making and Shaping of the Victorian Teacher: A Comparative New Cultural History
}

New York: Palgrave Macmillan, 2011. 224 pp.

\section{E.J. Errington}

Queen's University

We have all been students and many of us are teachers. And we all think that we know what makes a "good" teacher. As Marianne Larsen illustrates, our twenty-first century assumptions about the importance of education and of the key role that teachers play within the system eerily echo beliefs that first emerged in the Victorian age. This well-crafted and persuasive analysis of The Making and Shaping of the Victorian Teacher explores how education reformers and soon the state "invented" the model teacher and how these expectations were embedded and reinforced by new practices that effectively governed teachers' lives and their work.

Larsen is clear from the beginning that this is not a collective biography. Instead, she seeks to examine "how it became possible to think about teachers in new ways" (22) and how the ideas and subsequent processes that were championed by Victorian reformers were instrumental in making "good" teachers. This is a decidedly cultural history that rests, as Larsen explains in Part One, on a close reading of the emerging discourses about educational reform. The first section of the book also places her subject firmly into a comparative context. Concerns raised by growing industrialization and urbanization encouraged educational reformers throughout Europe and North America to call for free and eventually compulsory education as a way to address social ills and ensure the well being of the state. Although educational systems differed, educational reformers, migrants and the emerging education press promoted a cross fertilisation of ideas and assumptions about the benefits of popular education.

Part Two explores how teachers became the object of concern amid this new vision of the educational state. At the beginning of the century teachers were viewed with disdain. Teaching, after all, was "a refuge for the destitute individual" and most teachers were old, sick, ignorant, immoral, cruel and clearly unable to manage increasingly 
unruly pupils. This new school system required "good" teachers and two models emerged in the discourse about what constituted the effective Victorian teacher. The "modern" teacher understood pedagogy, as well has having extensive knowledge in those subjects considered necessary for Victorian pupils. The "moral" teacher was to be "an exemplary Christian role model" (91) who assumed a quasi parental role, cheerfully nurturing her charges and ensuring they imbibed the moral and religious sensibilities essential for an orderly society. As Larsen skilfully points out, these two models were distinctly gendered and this had a direct impact on how teachers were taught their profession. Training institutions for the "modern" male teacher included classes on detailed subject matter (mathematics, the classics, etc) while those for the moral, female teacher included needlework and domestic economy.

Having identified the attributes of the good teacher, reformers and soon the state set out to "make" teachers who conformed to these ideas. As Larsen points out in the first chapter of Part Three, schools were not just institutions to control and to shape students. They were also sites where teachers "became visible and hence governable." Initially, parents and expectations of the local community had a direct impact on how and what teachers taught. By mid-century, voluntary societies and soon the state became increasingly involved in monitoring and disciplining teachers in the classroom. School visitors and inspectors not only "advised" the teacher about her/his craft but also judged their performance, and if it was found wanting, had the power to withhold pay or dismiss teachers altogether. As Larsen concludes, "these disciplinary mechanisms hung over the teacher's head as a sword of Damocles" (123). Even before they entered their own classroom, student teachers were the subject of discipline and control. From admission standards that privileged candidates who were healthy and moral, to complete control over student-teachers' every moment, teacher training institutions consciously operated to regulate every aspect of prospective teachers' lives. Such external elements of control, including increasingly formal examinations, became internalized by teachers themselves - and what had been the mantra of educational reformers became a way in which teachers judged themselves as modern and moral beings.

The Making and Shaping of the Victorian Teacher is a fascinating read. Larsen has a finely tuned eye for the complexity of her subject and is sensitive to the apparent contradictions within the discourse. As an explicitly cultural history that is rooted in a sophisticated appreciation of Foucault, Larsen offers a convincing analysis that rests on a careful reading of a variety of sources. The comparative element that is sustained throughout the text illustrates how what we would consider "globalization" was well in train in the nineteenth century. The lengthy explanations of the theoretical perspective could have been pared down substantially (although for those not familiar with cultural history, it does provide a clear primer). And I would have appreciated a bibliography that divided primary and secondary sources. But this is quibbling. Making and Shaping the Victorian Teacher offers us an intriguing and convincing look at the world of this new Victorian "profession" and for those of us who have taught or now teach public school, it also offers some uncanny and at times disturbing echoes of current concerns about the place and role of the teacher and their relationship to the state. 